\title{
Antenatal lifestyle advice for women who are overweight or obese: LIMIT randomised trial
}

\author{
(c) $(1)$ (8) OPEN ACCESS
}

\begin{abstract}
Jodie M Dodd professor of obstetrics and gynaecology; maternal fetal medicine specialist ${ }^{12}$, Deborah Turnbull professor of psychology ${ }^{3}$, Andrew J McPhee director of neonatal medicine ${ }^{4}$, Andrea R Deussen senior clinical trials coordinator ${ }^{1}$, Rosalie M Grivell senior lecturer in obstetrics and gynaecology; maternal fetal medicine specialist ${ }^{12}$, Lisa N Yelland senior statistician ${ }^{1}$, Caroline A Crowther professor of obstetrics and gynaecology ${ }^{1}$, Gary Wittert professor medicine ${ }^{5}$, Julie A Owens head of school paediatrics and reproductive health; associate dean, research ${ }^{1}$, Jeffrey S Robinson professor of obstetrics and gynaecology ${ }^{1}$, for the LIMIT Randomised Trial Group
\end{abstract}

${ }^{1}$ Robinson Institute and School of Paediatrics and Reproductive Health, University of Adelaide, 72 King William Road, North Adelaide, South Australia, Australia 5006; 'Department of Perinatal Medicine, Women's and Babies Division, Women's and Children's Hospital, 72 King William Road, North Adelaide, South Australia, Australia 5006; ${ }^{3}$ School of Psychology, University of Adelaide, Adelaide, South Australia, Australia 5005; ${ }^{4}$ Department of Neonatal Medicine, Women's and Babies Division, Women's and Children's Hospital, 72 King William Road, North Adelaide, South Australia, Australia 5006; ${ }^{5}$ School of Medicine, University of Adelaide, Adelaide, South Australia, AUSTRALIA 5005

\begin{abstract}
Objective To determine the effect of antenatal dietary and lifestyle interventions on health outcomes in overweight and obese pregnant women.

Design Multicentre randomised trial. We utilised a central telephone randomisation server, with computer generated schedule, balanced variable blocks, and stratification for parity, body mass index (BMI) category, and hospital.

Setting Three public maternity hospitals across South Australia.

Participants 2212 women with a singleton pregnancy, between 10+0 and $20+0$ weeks' gestation, and $\mathrm{BMI} \geq 25$.

Interventions 1108 women were randomised to a comprehensive dietary and lifestyle intervention delivered by research staff; 1104 were randomised to standard care and received pregnancy care according to local guidelines, which did not include such information.

Main outcome measures Incidence of infants born large for gestational age (birth weight $\geq 90$ th centile for gestation and sex). Prespecified secondary outcomes included birth weight $>4000 \mathrm{~g}$, hypertension, pre-eclampsia, and gestational diabetes. Analyses used intention to treat principles.
\end{abstract}

Results 2152 women and 2142 liveborn infants were included in the analyses. The risk of the infant being large for gestational age was not significantly different in the two groups (lifestyle advice 203/1075 (19\%) $v$ standard care $224 / 1067$ (21\%); adjusted relative risk $0.90,95 \%$ confidence interval 0.77 to $1.07 ; P=0.24$ ). Infants born to women after lifestyle advice were significantly less likely to have birth weight above $4000 \mathrm{~g}$ (lifestyle advice 164/1075 (15\%) v standard care 201/1067 (19\%); $0.82,0.68$ to 0.99 ; number needed to treat (NNT) 28, 15 to 263 ; $P=0.04$ ). There were no differences in maternal pregnancy and birth outcomes between the two treatment groups.

Conclusions For women who were overweight or obese, the antenatal lifestyle advice used in this study did not reduce the risk delivering a baby weighing above the 90th centile for gestational age and sex or improve maternal pregnancy and birth outcomes.

Trial registration Australian and New Zealand Clinical Trials Registry (ACTRN12607000161426).

\section{Abstract \\ Introduction}

The World Health Organization has identified obesity as a health problem of global importance, ${ }^{1}$ contributing to the burden of disease through an increased risk of cardiovascular disease and diabetes and their complications. ${ }^{2}$ Overweight and obesity are commonly encountered during pregnancy, with about half of women entering pregnancy with a body mass index (BMI) $\geq 25$. $^{34}$

The risks associated with overweight and obesity during pregnancy are well documented and increase with increasing BMI. ${ }^{5}$ Maternal complications include an increased risk of hypertension and pre-eclampsia, ${ }^{5-7}$ gestational diabetes,${ }^{5-7}$ need 
for both induction of labour and caesarean section, ${ }^{5-7}$ and perinatal death. ${ }^{89}$ Infants born to overweight or obese women are more likely to be macrosomic, ${ }^{6-9}$ be admitted to intensive care, ${ }^{569}$ and require treatment for jaundice or hypoglycaemia. ${ }^{56}$ Furthermore, population studies consistently identify both maternal overweight and obesity and high infant birth weight (variably defined as birth weight above the 90th centile for gestational age or birth weight above $4000 \mathrm{~g}$ or $4500 \mathrm{~g}$ ) as important risk factors for the development of early infant ${ }^{10}$ and childhood obesity. ${ }^{11}$

Substantial literature on maternal weight gain in pregnancy has been summarised by the Institute of Medicine. ${ }^{12}$ Several population based cohort studies have evaluated the effect of varying degrees of gestational weight gain on pregnancy outcomes for women who are overweight or obese, suggesting that, compared with higher weight gain, weight gain within the recommendations of the Institute of Medicine is associated with a reduced risk of maternal complications and of infants being born large for gestational age. ${ }^{13-16}$ Most small randomised trials to date evaluating antenatal dietary and lifestyle interventions in women who are overweight or obese have primarily focused on limiting gestational weight gain, often as a surrogate measure for clinical outcomes, based on the assumption that lower weight gain will in turn improve outcomes in pregnancy and childbirth. While meta-analyses indicate that interventions seem effective in limiting gestational weight gain, the effect on maternal and perinatal outcomes, which have been under-reported, remains to be determined. ${ }^{17-19}$

We conducted a randomised trial to evaluate whether provision of antenatal lifestyle advice to overweight or obese pregnant women was effective in improving maternal and infant health outcomes.

\section{Methods \\ Participants}

Women were recruited between June 2008 and December 2011 from the three major metropolitan maternity hospitals within Adelaide, South Australia. Women were eligible if they had a BMI $\geq 25$ and singleton pregnancy at $10+0$ to 20+0 weeks' gestation. Women with type 1 or 2 diabetes diagnosed before pregnancy were ineligible. Each participant provided written informed consent, and the ethics committee at each collaborating hospital approved the protocol. ${ }^{20}$

\section{Randomisation, allocation concealment, and blinding}

All pregnant women presenting for antenatal care at the participating centres had their height and weight measured and BMI calculated at their first antenatal appointment. A research assistant counselled eligible women and then randomised them to receive lifestyle advice or standard care by telephoning the central randomisation service. The computer generated randomisation schedule used balanced variable blocks in the ratio 1:1 and was prepared by an investigator not involved with recruitment or clinical care. Stratification occurred for parity $(0$ $v \geq 1)$, BMI at antenatal booking (25-29.9 $v \geq 30)$, and collaborating centre. Outcome assessors were blinded to the treatment group allocated.

\section{Intervention-lifestyle advice}

Women randomised to lifestyle advice participated in a comprehensive dietary and lifestyle intervention over the remainder of their pregnancy that included a combination of dietary, exercise, and behavioural strategies delivered by a research dietician and trained research assistants. ${ }^{20}$ Women were provided with dietary advice consistent with current Australian standards ${ }^{21}$ to maintain a balance of carbohydrates, fat, and protein and to reduce intake of foods high in refined carbohydrates and saturated fats, while increasing intake of fibre and promoting consumption of two servings of fruit, five servings of vegetables, and three servings of dairy each day. ${ }^{21}$ Physical activity advice primarily encouraged women to increase their amount of walking and incidental activity. ${ }^{22}$ Tailoring of the intervention was informed by stage theories of health decision making. ${ }^{23}$

Within two weeks of randomisation, women attended a planning session with a research dietician, during which a detailed dietary and exercise history was obtained. Women were provided with individualised information, including meal plans, healthy recipes that were quick to prepare, simple food substitutions (including reducing sugar sweetened soft drinks and fruit juices, reducing added sugar and foods high in refined carbohydrates, and low fat alternatives), options for healthy snacking and eating out, and guidelines for healthy food preparation. Women were encouraged to set achievable goals for dietary and exercise change, supported to make these lifestyle changes, and asked to self monitor their progress through the use of a work book provided. Women were encouraged to identify potential barriers to implementation of their dietary and physical activity goals. Using these perceived barriers, women were assisted to problem solve and to develop individualised strategies to facilitate their successful implementation. This information was reinforced during subsequent inputs provided by the research dietician (at 28 weeks' gestation) and trained research assistants (via telephone call at 22, 24, and 32 weeks' gestation and a face to face visit at 36 weeks' gestation).

\section{Standard care}

Women randomised to standard care continued to receive their pregnancy care according to state-wide perinatal practice and local hospital guidelines, which during the course of the trial did not include routine provision of advice related to diet, exercise, or gestational weight gain. ${ }^{24}$

\section{Follow-up of women in both groups}

All women had their ongoing clinical care provided by clinicians at their planned hospital of birth. Consistent with state-wide perinatal practices, all women were encouraged to undergo screening for gestational diabetes. ${ }^{25}$ After birth, a research assistant not involved in providing the intervention and blinded to treatment allocation obtained information relating to antenatal, birth, and infant outcomes from the case notes.

\section{Outcomes}

The primary outcome was the incidence of infants born large for gestational age (birth weight $\geq 90$ th centile for gestational age and infant sex).$^{26}$ While large for gestational age, high infant birth weight, and infant macrosomia (variably defined as birth weight above $4000 \mathrm{~g}$ or $4500 \mathrm{~g}$ ) are often used clinically, incorporation of a birthweight centile for gestational age was considered important, reflecting the possibility that the intervention might modify fetal growth across pregnancy and therefore plausibly mediate high infant birth weight across the gestational age spectrum.

Prespecified secondary infant outcomes included preterm birth (before 37 weeks); mortality (stillbirth (intrauterine fetal death after 20 weeks' gestation and before birth), or infant death (death 
of a liveborn infant before hospital discharge, excluding lethal congenital anomalies)); weight $>4000$ g; hypoglycaemia requiring intravenous treatment; admission to neonatal intensive care unit or special care baby unit; hyperbilirubinaemia requiring phototherapy; nerve palsy (peripheral nerve injury, including spinal cord injury, present at discharge from hospital); fracture (basal skull or other fracture identified at birth); birth trauma (subdural or intracerebral haemorrhage, spinal cord injury, or peripheral nerve injury present at hospital discharge); or shoulder dystocia (one or more of moderate traction, suprapubic pressure, lithotomy position, McRoberts manoeuvre, rotation into the oblique plane, delivery of the posterior shoulder, cleidotomy, symphysiotomy, or Zavanelli manoeuvre to deliver the fetal shoulders).

Prespecified secondary maternal outcomes included hypertension (systolic blood pressure $\geq 140 \mathrm{~mm} \mathrm{Hg}$ and/or diastolic $\geq 90 \mathrm{~mm} \mathrm{Hg}$ on two occasions four or more hours apart) and pre-eclampsia ${ }^{27}$; gestational diabetes (positive $75 \mathrm{~g}$ oral glucose tolerance test result with fasting blood glucose $\geq 5.5$ $\mathrm{mmol} / \mathrm{L}$ or 2 hour $\geq 7.8 \mathrm{mmol} / \mathrm{L})^{25}$; need for and length of antepartum hospital stay; antepartum haemorrhage requiring stay in hospital; preterm ruptured membranes before labour; term ruptured membranes before labour; chorioamnionitis requiring antibiotics during labour; need for induction of labour; antibiotic use during labour; caesarean section; postpartum haemorrhage ( $>600 \mathrm{~mL}$ ); perineal trauma; wound infection; endometritis; antibiotics postpartum; postpartum length of hospital stay; thromboembolic disease; and maternal death.

In a post hoc analysis, we categorised gestational weight gain (defined as the difference in weight measured between 36 weeks' gestation (or closest to birth) and the antenatal booking visit) as the proportion of women whose weight gain was below, within, or exceeded the Institute of Medicine recommendations based on early BMI category. ${ }^{12}$

\section{Statistical analysis}

Analyses were performed on an intention to treat basis, according to the treatment group allocated at randomisation. Multiple imputation was performed separately by treatment group with chained equations to create 100 complete datasets. Sensitivity analyses with the available data and different imputation models produced similar results. Binary outcomes were analysed with log binomial regression, with treatment effects expressed as relative risks, or Fisher's exact tests. Continuous outcomes were analysed with linear regression, with treatment effects expressed as differences in means. Count outcomes were analysed with Poisson regression, or negative binomial regression where overdispersion was present, with treatment effects expressed as ratios of means.

Both unadjusted and adjusted analyses were performed, with adjustment for the stratification variables. Outcomes derived from birth weight were additionally adjusted for maternal age, socioeconomic status, and maternal smoking. Significance was set at $\mathrm{P}<0.05$ (two sided) with no adjustment for multiple comparisons. All analyses followed a prespecified analysis plan with SAS v9.3 (Cary, NC, US). Post hoc outcomes are clearly identified and no imputation was performed.

We estimated that a sample size of 2180 women would have $80 \%$ statistical power (two tailed $\alpha$ level 0.05 ) to detect a $30 \%$ relative reduction ${ }^{28}$ in the occurrence of infants born large for gestational age from $14.4 \%$ to $10.1 \%$, allowing for $15 \%$ attrition. $^{3}$

\section{Results}

The figure outlines the flow of participants in the trial $\Downarrow$. A total of 2152 women and 2142 liveborn infants were included in the intention to treat analyses. There were two maternal deaths (motor vehicle collision in lifestyle advice group; and ruptured maternal splenic artery aneurysm in standard care group). There were 10 stillborn infants (two from placental abruption, one from severe intrauterine growth restriction, one from acute chorioamnionitis, and one from motor vehicle collision in lifestyle advice group; and two from placental insufficiency, one from obstetric cholestasis, and two unexplained in standard care group) and two neonatal deaths (excluding lethal congenital anomalies) from complications of extreme prematurity, one in each group.

Table $1 \Downarrow$ outlines the baseline demographics and clinical characteristics of participants. The median BMI of the cohort was 31.1 (interquartile range $27.9-35.8$ ), with $42.1 \%$ of women being overweight and $57.9 \%$ obese. Of women randomised to lifestyle advice, $86.7 \%$ attended their first dietary appointment and $77.2 \%$ the second. Adequate data were available for 2127 (99.3\%) infants for the primary outcome. Missing values for the 15 remaining infants were imputed as described above.

There was no significant difference in the risk of infants born large for gestational age in the lifestyle advice group compared with standard care group (203/1075 (19\%) v 224/1067 (21\%); adjusted relative risk $0.90,95 \%$ confidence interval 0.77 to 1.07 ; $\mathrm{P}=0.24$ ) (table $2 \Downarrow$ ). Infants born to women allocated to lifestyle advice, however, were less likely to weigh above $4000 \mathrm{~g}$ (164/1075 (15\%) v 201/1067 (19\%); 0.82, 0.68 to 0.99; number needed to treat (NNT) 28,15 to $263 ; \mathrm{P}=0.04$ ) when compared with infants born to women allocated to standard care.

There was no significant difference in preterm birth before 37 weeks or infant admission to neonatal intensive care or special care unit (table $2 \Downarrow$ ). For women, there were no significant differences in risk of antenatal (table 3) $\Downarrow$, labour, or birth (table 4) $\Downarrow$ complications after the lifestyle intervention compared with standard care.

In a post hoc analysis, there was no difference in total gestational weight gain (9.39 (SD 5.74) kg in the lifestyle advice group $v$ 9.44 (SD 5.77) $\mathrm{kg}$ in standard care; adjusted mean difference $-0.04,-0.55$ to $0.48 ; \mathrm{P}=0.89$ ) between the two groups (table $5 \Downarrow$ ). Furthermore, there were no significant differences between the two treatment groups in the proportion of women whose weight gain was below, within, or exceeded the Institute of Medicine recommendations based on BMI in early pregnancy (table $5 \Downarrow)^{12}$

\section{Discussion \\ Principal findings}

Our findings indicate that provision of lifestyle advice to women who are overweight or obese during pregnancy does not reduce the risk of infants born large for gestational age or improve maternal outcomes of pregnancy and birth but is associated with a significant reduction in the risk of birth weight above $4000 \mathrm{~g}$.

\section{Strengths and limitations}

Our randomised trial has several strengths, including being the largest to date to evaluate the effect of an antenatal lifestyle intervention for overweight or obese women. Our trial used robust methods, including prospectively measured height, weight, and BMI in all participants, central randomisation, and blinding of outcome assessors. Furthermore, the trial had a 
prespecified sample size that was achieved, had prespecified primary and secondary outcomes of clinical relevance, followed a prespecified analysis plan, and achieved a high rate of follow-up of participants. We had few exclusion criteria, and the intensity of the intervention was realistically achievable within current publicly funded models of provision of antenatal care.

In contrast with the findings reported in systematic reviews evaluating dietary interventions in overweight or obese pregnant women, ${ }^{17-19}$ which included smaller randomised trials, often of low methodological quality, we did not identify differences in mean gestational weight gain. While there has been considerable variation in the intensity of interventions provided across trials, ${ }^{17-19}$ ranging from single sessions with a dietician up to additional dietetic counselling sessions at each antenatal visit, most trials provided between three and six intervention sessions over the course of pregnancy. The intensity of our intervention was consistent with this approach, involving three face to face sessions and three telephone contacts and, importantly, was considered feasible to implement within current publicly funded models of maternity care. While increasing the intensity of the intervention might have resulted in differences in gestational weight gain, we consider this an impractical approach, both from a healthcare perspective where resources are limited, and from an individual woman's perspective where additional attendance for visits could further affect compliance.

Furthermore, it will be important to assess the economic costs associated with providing the described moderate intensity intervention in our planned detailed evaluation.

A potential limitation of our trial is the generalisability and external validity of our findings, our population being predominantly white and of high social disadvantage, with $60 \%$ of eligible women declining to participate, reflecting both a lack of interest and time because of other commitments. Furthermore, not all women attended scheduled appointments with the dietitian, with only $87 \%$ attending their first and $77 \%$ their second dietary sessions. Compliance with intervention in trials involving overweight and obese pregnant women has been poorly reported in the literature to date. ${ }^{17-19}$ Of note, the Danish randomised trial by Vinter and colleagues ${ }^{29}$ reported higher rates of attendance than were achieved in our trial, probably reflecting differences in characteristics of the study population, the women being of higher socioeconomic and educational status than the participants in our trial.

\section{Comparison with other studies}

Our findings highlight the difficulties in limiting gestational weight gain at a population level, with $42 \%$ of women gaining in excess of the Institute of Medicine recommendations. ${ }^{12}$ Research efforts to date have focused on limiting gestational weight gain, to the exclusion of adequate evaluation of relevant maternal and perinatal outcomes, based on a plausible assumption, although relatively untested by randomised trials, that lower weight gain results in improved outcomes in pregnancy and childbirth. Gestational weight gain as a measure incorporates the effects of maternal fat deposition, pregnancy related plasma volume expansion, peripheral oedema, placental mass, fetal mass, and amniotic fluid volume. It is difficult, however, to separate the relative contribution of each of these components, with maternal deposition of adipose tissue likely to have the greatest causal impact in terms of both short term pregnancy related outcomes and the longer term health of the child. ${ }^{30}$
While the effect of any changes in maternal dietary intake, including specific nutritional components, and physical activity on in utero growth remains to be determined, observational studies suggest that consumption of a diet high in polyunsaturated fatty acids is associated with reduced early childhood adiposity as measured by skinfold thickness ${ }^{31}$ and predictive of fat mass determined by DEXA at ages 4 and 6 years. ${ }^{32}$ Together, these findings highlight the potential impact of relatively modest changes in the quality of maternal diet on in utero growth and future childhood adiposity.

We did not find a difference in the risk of infants born large for gestational age, although our intervention was associated with a significant reduction in the risk of an infant being born weighing above $4000 \mathrm{~g}$. This reduction in the proportion of infants with birth weight above $4000 \mathrm{~g}$ could reflect a chance event, which occurred despite a non-significant reduction in the risk of preterm birth and a non-significant increase in gestational diabetes for women receiving lifestyle advice. Alternately, however, these findings are consistent with those of Sebire and colleagues,${ }^{33}$ who, using a large UK population based cohort, showed that while infants born to overweight or obese women were more likely to have weight at the upper end of the spectrum, there was little change in the remainder of the distribution compared with infants born to women of normal BMI. ${ }^{33}$ While this is similar to the birthweight findings in our standard care group, it is plausible that our intervention successfully reduced the proportion of infants with high birth weight. As infant birth weight above $4000 \mathrm{~g}$ was a secondary outcome in our trial, it will be important to evaluate this finding in ongoing randomised trials evaluating the effect of dietary interventions in obese women. ${ }^{34}$

The immediate consequences of infant macrosomia and its associated effects on delivery are well described. ${ }^{35}$ There is, however, increasing evidence of a persisting longer term health legacy, with birth weight above $4000 \mathrm{~g}$ independently associated with an increased risk of overweight and obesity in childhood and adulthood. ${ }^{36}{ }^{37}$ Specifically, birth weight greater than 4000 $\mathrm{g}$ has been associated with a twofold increased risk of obesity at age 4 years ${ }^{38} 39$ and beyond, ${ }^{36}{ }^{37}$ highlighting the public health importance of high birth weight and of evaluating interventions that target the in utero environment in the short and long term prevention of obesity. ${ }^{40}$ It will therefore be important to continue to follow-up the infants born to women in this trial to evaluate if there is any effect of the observed $18 \%$ relative risk reduction in incidence of birth weight above $4000 \mathrm{~g}$ on subsequent early childhood obesity.

\section{Conclusions and policy implications}

To date, there has been a lack of robust clinical outcome data from randomised trials on the effects of providing an antenatal dietary and lifestyle intervention for pregnant women who are overweight or obese, the research focus being on "gestational weight gain, at the expense of adequate power for clinical outcomes." ${ }^{41}$ Our trial dealt with this highlighted gap in the literature. Our results indicate that while provision of an antenatal dietary and lifestyle intervention did not reduce the incidence of infants born large for gestational age, it was effective in reducing the risk of high infant birth weight, above $4000 \mathrm{~g}$. The intervention provided was not associated with improvements in the various maternal pregnancy and birth outcomes, which are documented to occur more commonly among women who are overweight or obese. While a more intensive intervention might be effective in modifying these risks, there are important considerations both in relation to the cost of providing such an intervention and maternal compliance, 
which might impact feasibility. Alternate approaches might entail the use of drugs, including metformin, which is currently being evaluated..$^{42}$

We are indebted to all the women who participated in this randomised trial.

The following people and institutions (in Adelaide, South Australia, unless indicated otherwise) participated in the LIMIT Trial:

Steering group-JMD, DT, AMcP, RMG, CAC, M Gillman (Obesity Prevention Program, and Harvard University, Boston, Massachusetts, US), GW, JAO, JSR.

Coordinating team—JMD, ARD, RMG, LNY, L Moran, C Cramp, A Newman, L Kannieappian, S Hendrijanto, M Kelsey, J Beaumont, C Danz, J Koch, A Webber, C Holst, K Robinson, S Zhang, V Ball, K Ball, H Deussen, N Salehi, R Bartley, R Stafford-Green, S Ophel, M Cooney, M Szmeja, A Short, A Melrose, S Han, I Mohamad, L Chapple. Adverse events committee-RMG, J Svigos, V Bhatia, N Manton. Collaborating Hospitals (total number of women recruited from each site in parentheses), *indicates named associate investigator for the NHMRC grant.

Flinders Medical Centre (South Australia) ( $n=669)$ : J McGavigan*, R Bryce, S Coppi, C Fanning, G Hannah, M Ignacio, H Pollard, F Schmidt, Y Shinners

Lyell McEwin Hospital (South Australia) ( $n=505)$ : G Dekker*, S Kennedy-Andrews, R Beaven, J Niven, S Burgen, J Dalton, N Dewhurst, L Forst, V Mugg, C Will, H Stone

Women's and Children's Hospital (South Australia) $(n=1038)$ : JMD, JSR, ARD, CAC*, C Wilkinson*, H Purcell, J Wood, D Press, K Ralph, S Donleavy, S Seager, F Gately, A Jolly, L Lahnstein, S Harding, K Daw, M Hedges, R Fraser-Trumble

Contributors: All authors were involved equally in the development and design of the trial, the conduct of the trial, drafting of the manuscript, and revision for intellectual content and approved the final submitted version. LNY carried out the statistical analyses. JMD is guarantor.

Funding: This project was funded by a four year project grant from the National Health and Medical Research Council (NHMRC), Australia (ID 519240). JMD is supported through a NHMRC Practitioner Fellowship (ID 627005). The funder had no role in the study design, data collection, analysis, interpretation, or writing of the report.

Competing interests: All authors have completed the ICMJE uniform disclosure form at www.icmje.org/coi_disclosure.pdf and declare: no support from any organisation for the submitted work; no financial relationships with any organisations that might have an interest in the submitted work in the previous three years; no other relationships or activities that could appear to have influenced the submitted work.

Ethical approval: This study was approved by each of the collaborating sites (Research Secretariat, Women's and Children's Hospital (application REC 1839/6/2012); Ethics of Human Research Committee, The Queen Elizabeth Hospital and Lyell McEwin Hospital (application 2008033); and Flinders Clinical Research Ethics Committee, Flinders Medical Centre (Application 128/08)). Each participant provided written informed consent,

Data sharing: No additional data available.

Transparency: The lead author and manuscript guarantor (JMD) affirms that the manuscript is an honest, accurate, and transparent account of the study being reported; that no important aspects of the study have been omitted; and that any discrepancies from the study as planned and registered have been explained.

World Health Organization. Obesity: preventing and managing the global epidemic. World Health Organ Tech Rep Ser 2000;894:1-253.

2 Ezzati M, Lopez AD, Rodgers A, Vander Hoorn S, Murray CJ, for the Comparative Risk Assessment Collaborating Group. Selected major risk factors and global and regional burden of disease. Lancet 2002;360:1347-60.
3 Scheil, W, Scott J, Catcheside B, Sage L. Pregnancy outcome in South Australia 2010. Pregnancy Outcome Unit SA Health, Government of South Australia, Adelaide, 2012.

4 Chu SY, Kim SY, Bish CL. Prepregnancy obesity prevalence in the United States, 2004-2005. Maternal Child Health J 2008;13:614-20.

5 Callaway LK, Prins JB, Chang AM, McIntyre HD. The prevalence and impact of overweight and obesity in an Australian obstetric population. Med J Aust 2006;184:56-9.

6 Dodd JM, Grivell RM, Nguyen A-M, Chan A, Robinson JS. Maternal and perinatal health outcomes by body mass index category. Aust N Z J Obstet Gynaecol 2011;51:136-40.

7 Abenhaim HA, Kinch RA, Morin L, Benjamin A, Usher R. Effect of prepregnancy body mass index categories on obstetrical and neonatal outcomes. Arch Gynecol Obstet 2007;275:39-43.

8 Cedergren MI. Maternal morbid obesity and the risk of adverse pregnancy outcome. Obstet Gynecol 2004;103:219-24.

9 Cnattingius S, Bergstrom R, Lipworth L, Kramer MS. Prepregnancy weight and the risk of adverse pregnancy outcomes. N Engl J Med 1998;338:147-52.

10 Tikellis G, Ponsonby AL, Wells JC, Pezic A, Cochrane J, Dwyer T. Maternal and infant factors associated with neonatal adiposity: results from the Tasmanian Infant Health Survey. Int J Obestet 2012;36:496-504.

11 Fraser A, Tilling K, Macdonald-Wallis C, Sattar N, Brion MJ, Benfield L, et al. Association of maternal weight gain in pregnancy with offspring obesity and metabolic and vascular traits in childhood. Circulation 2010;121:2557-64.

12 Rasmussen KM, Yaktine AL, eds. Weight gain during pregnancy: reexamining the guidelines. Institute of Medicine, 2009

13 Cedergren Ml. Effects of gestational weight gain and body mass index on obstetric outcomes in Sweden. Int J Gynecol Obstet 2006;93:269-74.

14 Cedergren MI. Optimal gestational weight gain for body mass index categories. Obstet Gynecol 2007;110:759-64.

15 Nohr EA, Bech BH, Davies MJ, Frydenberg M, Henriksen TB, Olsen J. Prepregnancy obesity and fetal death: a study within the Danish National Birth Cohort. Obstet Gynecol 2005;106:250-9.

16 Kiel DW, Dodson EA, Artal R, Boehmer TK, Leet TL. Gestational weight gain and pregnancy outcomes in obese women: how much is enough? Obstet Gynecol 2007;110:752-8.

17 Dodd JM, Grivell RM, Crowther CA, Robinson JS. Antenatal interventions for overweight or obese pregnant women: a systematic review of randomised trials. Br J Obstet Gynaecol 2010;117:1316-26.

18 Oteng-Ntim E, Varma R, Croker H, Poston L, Doyle P. Lifestyle interventions for overweigh and obese pregnant women to improve pregnancy outcome: systematic review and meta-analysis. BMC Med 2012;10:10:47.

19 Thangaratinam S, Rogozinska E, Jolly K, Glinkowski S, Roseboom T, Tomlinson JW, et al. Effects of interventions in pregnancy on maternal weight and obstetric outcomes: meta-analysis of randomised evidence. BMJ 2012;344:e2088.

20 Dodd JM, Turnbull DA, McPhee AJ, Wittert G, Crowther CA, Robinson JS. Limiting weight gain in overweight and obese women during pregnancy to improve health outcomes: the LIMIT randomised controlled trial. BMC Pregnancy Childbirth 2011:11:79.

21 Australian Guide to Healthy Eating. Australian Government Department of Health, 2008. www.health.gov.au/internet/main/publishing.nsf/content/health-pubhlth-publicat-documentfdcons-cnt.htm.

22 Royal College of Obstetricians and Gynaecologists. Recreational exercise and pregnancy: information for you. RCOG Press, 2006.

23 Bennett P, Murphy S. Psychology and health promotion. Open University Press, 1997.

24 South Australian Perinatal Practice Guidelines: normal pregnancy, labour and puerperium. Government of Australia, SA Health, 2013. www.health.sa.gov.au/ppg/Default.aspx? PageContent $\mid \mathrm{D}=2248 \&$ tabid $=54$

25 South Australian Perinatal Practice Guidelines: diabetes mellitus and abnormal glucose tolerance Government of Australia, SA Health, 2013. www.health.sa.gov.au/ppg/Default. aspx?PageContentID $=2118 \&$ tabid $=100$

26 Beeby PJ, Bhutap T, Taylor LK. New South Wales population based birthweight percentile charts. J Paediatr Child Health 1996;32:512-8.

27 Brown MA, Hague WM, Higgins J, Lowe S, McCowan L, Oats J, et al. The detection, investigation and management of hypertension in pregnancy: full consensus statement. Aust N Z J Obstest Gynaecol 2000;40:139-55.

28 Crowther CA, Hiller JE, Moss JR, McPhee AJ, Jeffries WS, Robinson JS, et al. Effect of treatment of gestational diabetes mellitus on pregnancy outcomes. N Engl J Med 2005;352:2477-86

29 Vinter CA, Jensen DM, Ovesen P, Beck-Nielsen H, Jørgensen JS. The LiP (Lifestyle in Pregnancy) study: a randomized controlled trial of lifestyle intervention in 360 obese pregnant women. Diabetes Care 2011;34:2502-7.

30 Lawlor DA, Relton C, Sattar N, Nelson SM. Maternal adiposity—a determinant of perinatal and offspring outcomes? Nat Rev Endocrinol 2012;8:679-88.

31 Donahue SM, Rifas-Shiman SL, Gold DR, Jouni ZE, Gillman MW, Oken E. Prenatal fatty acid status and child adiposity at age $3 \mathrm{y}$ : results from a US pregnancy cohort. Am J Clin Nutr 2011;93:780-8.

32 Moon RJ, Harvey NC, Robinson SM, Ntani G, Davies JH, Inskip HM, et al. Maternal plasma polyunsaturated fatty acid status in late pregnancy is associated with offspring body composition in childhood. J Clin Endocrinol Metab 2013;98:299-307.

33 Sebire NJ, Harris JP, Wadsworth J, Joffe M, Beard RW, Regan L, et al. Maternal obesity and pregnancy outcome: a study of 287,213 pregnancies in London. Int $J$ Obes Relat Metab Disord 2001;25:1175-82

34 UPBEAT Trial. 2012. www.medscinet.net/upbeat/.

35 Dodd JM, Catcheside B, Scheil W. Can shoulder dystocia be reliably predicted? Aust N Z J Obstet Gynaecol 2012:52:248-52.

36 Schellong K, Schulz S, Harder T, Plagemann A. Birth weight and long term overweight risk: systematic review and meta-analysis including 643,902 persons from 66 studies and 26 countries globally. PLoS One 2012;7:e47776.

37 Yu ZB, Han SP, Zhu GZ, Zhu C, Wang XJ, Cao XG, et al. Birth weight and subsequent risk of obesity: a systematic review and meta-analysis. Obestet Rev 2011:12.525-42.

38 Kitsantas P, Gaffney KF. Risk profiles for overweight/obesity among preschoolers. Early Hum Dev 2010:86:563-8.

39 Rooney BL, Mathiason MA, Schauberger CW. Predictors of obesity in childhood adolescence, and adulthood in a birth cohort. Matern Child Health J 2010;15:1166-75.

40 Catalano PM. Obesity and pregnancy-the propagation of a viscous cycle? J Clin Endocrinol Metab 2003;88:3505-6.

41 Poston L, Chappell LC. How should women be advised on weight management in pregnancy? BMJ 2012;344:e2774 


\section{What is already known on this topic}

Overweight and obesity is common during pregnancy

Increasing maternal BMI and high gestational weight gain are both associated with an increased risk of complications during pregnancy and childbirth

Systematic reviews have indicated that while antenatal dietary and lifestyle interventions seem effective in limiting gestational weight gain, the effect on clinically relevant outcomes remains to be determined

\section{What this study adds}

The findings of this randomised trial indicate that providing a dietary and lifestyle intervention to pregnant women who are overweight or obese was not associated with a reduction in the incidence of infants born large for gestational age or in improving maternal pregnancy and birth outcomes

42 Norman JE. Efficacy of metformin in pregnant obese women: a randomised controlled trial, EMPOWaR. ISRCTN Register, 2011. http://isrctn.org/ISRCTN51279843.

43 Dodd JM. Metformin and dietary advice to improve insulin sensitivity and promote gestational restriction of weight in pregnant women who are obese: the GroW Randomised trial. ANZCTR Register, 2013 www.anzctr.org.au/Trial/Registration/TrialReview.aspx? id $=363282$.

Accepted: 24 January 2014

\section{Cite this as: BMJ 2014;348:g1285}

This is an Open Access article distributed in accordance with the Creative Commons Attribution Non Commercial (CC BY-NC 3.0) license, which permits others to distribute, remix, adapt, build upon this work non-commercially, and license their derivative works on different terms, provided the original work is properly cited and the use is non-commercial. See: http://creativecommons.org/licenses/by-nc/3.0/. 


\section{Tables}

Table 1| Baseline characteristics at trial entry in pregnant women with BMI $\geq 25$ randomised to lifestyle advice or standard care who did not withdraw consent to use data. Figures are numbers (percentage) of women unless stated otherwise

\begin{tabular}{|c|c|c|c|}
\hline Characteristic & Lifestyle advice $(n=1105)$ & Standard care $(n=1097)$ & Total $(n=2202)$ \\
\hline Mean (SD) maternal age (years) & $29.3(5.4)$ & $29.6(5.6)$ & $29.4(5.5)$ \\
\hline $\begin{array}{l}\text { Median (IQR) gestational age at entry } \\
\text { (weeks) }\end{array}$ & $14.0(11.9-17.0)$ & $14.1(11.9-17.0)$ & $14.1(11.9-17.0)$ \\
\hline Median (IQR) BMI & $31.0(28.1-35.9)$ & $31.1(27.7-35.6)$ & $31.1(27.9-35.8)$ \\
\hline \multicolumn{4}{|l|}{ BMI category: } \\
\hline $25.0-29.9$ & $458(41.4)$ & $468(42.7)$ & $926(42.1)$ \\
\hline $30.0-34.9$ & $326(29.5)$ & $318(29.0)$ & $644(29.2)$ \\
\hline $35.0-39.9$ & $202(18.3)$ & $183(16.7)$ & $385(17.5)$ \\
\hline$\geq 40.0$ & $119(10.8)$ & $128(11.7)$ & $247(11.2)$ \\
\hline Public patients & $1081(97.8)$ & $1067(97.3)$ & $2148(97.5)$ \\
\hline Mean (SD) weight $(\mathrm{kg})$ & $88.6(17.3)$ & $88.2(17.6)$ & $88.4(17.4)$ \\
\hline Mena (SD) height (cm) & $164.9(6.6)$ & $164.8(6.5)$ & $164.8(6.6)$ \\
\hline \multicolumn{4}{|l|}{ Race: } \\
\hline White & $995(90.0)$ & $998(91.0)$ & $1993(90.5)$ \\
\hline Asian & $26(2.4)$ & $34(3.1)$ & $60(2.7)$ \\
\hline Indian & $40(3.6)$ & $35(3.2)$ & $75(3.4)$ \\
\hline Other & $44(4.0)$ & $30(2.7)$ & $74(3.4)$ \\
\hline Smokers & $154(13.9)$ & $126(11.5)$ & $280(12.7)$ \\
\hline Nulliparous & $457(41.4)$ & $441(40.2)$ & $898(40.8)$ \\
\hline \multicolumn{4}{|l|}{ Previous: } \\
\hline Preterm birth & $57(5.2)$ & $59(5.4)$ & $116(5.3)$ \\
\hline Pre-eclampsia & $46(4.2)$ & $51(4.6)$ & $97(4.4)$ \\
\hline Stillbirth & $13(1.2)$ & $6(0.5)$ & $19(0.9)$ \\
\hline Neonatal death & $11(1.0)$ & $7(0.6)$ & $18(0.8)$ \\
\hline Caesarean section & $197(17.8)$ & $214(19.5)$ & $411(18.7)$ \\
\hline \multicolumn{4}{|l|}{ Family history of: } \\
\hline Diabetes & $288(26.1)$ & $290(26.4)$ & $578(26.2)$ \\
\hline Hypertension & $389(35.2)$ & $369(33.6)$ & $758(34.4)$ \\
\hline Heart disease & $187(16.9)$ & $179(16.3)$ & $366(16.6)$ \\
\hline \multicolumn{4}{|l|}{ Index of socioeconomic disadvantage*: } \\
\hline Unknown & $2(0.2)$ & $1(0.1)$ & $3(0.1)$ \\
\hline 1 (most disadvantaged) & $340(30.8)$ & $321(29.3)$ & $661(30.0)$ \\
\hline 2 & $271(24.5)$ & $264(24.1)$ & $535(24.3)$ \\
\hline 3 & $173(15.7)$ & $174(15.9)$ & $347(15.8)$ \\
\hline 4 & $150(13.6)$ & $178(16.2)$ & $328(14.9)$ \\
\hline 5 (least disadvantaged) & $169(15.3)$ & $159(14.5)$ & $328(14.9)$ \\
\hline
\end{tabular}

IQR=interquartile range; $B M I=$ body mass index.

*Socioeconomic index as measured by SEIFA (socioeconomic indexes for areas (www.abs.gov.au/websitedbs/censushome.nsf/home/seifa?opendocument\& navpos=260)) 
Table 2| Prespecified outcomes in infants born to women with BMI $\geq 25$ at trial entry by treatment group. Values are numbers (\%) of women and treatment effects are relative risks based on imputed data

\begin{tabular}{|c|c|c|c|c|}
\hline Outcome & $\begin{array}{l}\text { Lifestyle advice } \\
\qquad\left(\mathrm{n}=1075^{\star}\right)\end{array}$ & $\begin{array}{l}\text { Standard care } \\
\left(n=1067^{\star}\right)\end{array}$ & \multicolumn{2}{|c|}{ Treatment effect $(95 \% \mathrm{Cl}), \mathrm{P}$ value } \\
\hline Large for gestational age & $203(19)$ & $224(21)$ & 0.90 (0.76 to 1.07$), 0.23$ & 0.90 ( 0.77 to 1.07$), 0.24$ \\
\hline Major congenital anomaly & $25(2)$ & $14(1)$ & 1.76 (0.92 to 3.37 ), 0.09 & 1.77 (0.93 to 3.39 ), 0.08 \\
\hline Birth weight above $4000 \mathrm{~g}$ & $164(15)$ & $201(19)$ & 0.81 (0.67 to 0.98$), 0.03$ & 0.82 (0.68 to 0.99$), 0.04$ \\
\hline Hypoglycaemia requiring treatment & $107(10)$ & $103(10)$ & 1.03 (0.79 to 1.33 ), 0.85 & 1.02 (0.79 to 1.31$), 0.91$ \\
\hline Admission to NICU or SCBU & 394 (37) & $385(36)$ & 1.02 (0.91 to 1.14 ), 0.79 & 1.00 (0.90 to 1.12 ), 0.99 \\
\hline $\begin{array}{l}\text { Hyperbilirubinaemia requiring } \\
\text { phototherapy }\end{array}$ & $73(7)$ & $88(8)$. & 0.82 (0.61 to 1.11$), 0.19$ & 0.81 (0.60 to 1.09 ), 0.16 \\
\hline Nerve palsy & $4(0.4)$ & $2(0.2)$ & $(\mathrm{N} / \mathrm{A}), 0.69 \ddagger$ & NA \\
\hline Fracture & $4(0.4)$ & $2(0.2)$ & $(\mathrm{N} / \mathrm{A}), 0.69 \ddagger$ & NA \\
\hline Birth trauma & $6(0.6)$ & $7(0.7)$ & 0.85 (0.29 to 2.52$), 0.77$ & NA \\
\hline Shoulder dystocia & $44(4)$ & $35(3)$ & 1.25 (0.81 to 1.93$), 0.32$ & 1.25 (0.81 to 1.93 ), 0.32 \\
\hline
\end{tabular}

$\mathrm{NICU}=$ neonatal intensive care unit; $\mathrm{SCBU}=$ special care baby unit; $\mathrm{NA}=$ not applicable.

*Includes all liveborn infants.

†Adjusted analyses included stratification variables BMI category, parity and centre. Outcomes derived from birth weight were additionally adjusted for maternal age, socioeconomic status, and maternal smoking.

$\ddagger \mathrm{P}$ value derived Fisher's exact test. 
Table 3| Prespecified maternal antenatal outcomes in women with BMI $\geq 25$ at trial entry by treatment group. Values are numbers (\%) of women and treatment effects are relative risks based on imputed data unless otherwise indicated

\begin{tabular}{|c|c|c|c|}
\hline Outcome & Lifestyle advice $\left(n=1080^{\star}\right)$ & Standard care $\left(n=1073^{\star}\right)$ & Treatment effect (95\% Cl), P value \\
\hline Hypertension & $101(9)$ & $94(9)$ & 1.06 (0.81 to 1.39 ), 0.651 .05 ( 0.81 to 1.38 ), 0.70 \\
\hline Pre-eclampsia & $56(5)$ & $53(5)$ & 1.05 (0.73 to 1.51 ), 0.801 .03 ( 0.71 to 1.47 ), 0.89 \\
\hline Gestational diabetes & $148(14)$ & $120(11)$ & 1.22 (0.97 to 1.54 ), 0.091 .21 (0.96 to 1.52 ), 0.11 \\
\hline Antenatal admission & $166(15)$ & $191(18)$ & 0.86 ( 0.71 to 1.04$), 0.130 .86$ ( 0.71 to 1.04 ), 0.13 \\
\hline Mean (SD) antenatal length of stay ${ }^{*} \ddagger$ & $0.58(2.11)$ & $0.85(3.05)$ & 0.68 (0.50 to 0.93$), 0.020 .70$ (0.51 to 0.95$), 0.02$ \\
\hline Antepartum haemorrhage requiring admission & $16(1.5)$ & $16(1.5)$ & 0.99 (0.50 to 1.97$), 0.981 .00$ (0.50 to 1.98$), 0.99$ \\
\hline Preterm prelabour ruptured membranes & $9(0.8)$ & $19(1.8)$ & $0.47(0.21$ to 1.03$), 0.06$ \\
\hline Prelabour ruptured membranes at term & $9(0.8)$ & $9(0.9)$ & 0.99 (0.39 to 2.48$), 0.98$ \\
\hline
\end{tabular}

$\mathrm{NA}=$ not applicable.

*Includes all women who had liveborn or stillborn infant.

†Adjusted analyses included stratification variables BMI category, parity, and centre.

$\ddagger$ Treatment effects are ratios of means based on imputed data. 
Table 4| Prespecified labour and birth outcomes in women with BMI $\geq 25$ at trial entry by treatment group. Values are numbers (\%) of women and treatment effects are relative risks based on imputed data unless otherwise indicated

\begin{tabular}{|c|c|c|c|}
\hline Outcome & Lifestyle advice $\left(n=1075^{\star}\right)$ & Standard care $\left(n=1067^{\star}\right)$ & Treatment effect $(95 \% \mathrm{Cl}), \mathrm{P}$ value \\
\hline Preterm birth & $62(6)$ & $83(8)$ & 0.75 (0.54 to 1.03 ), 0.070 .74 (0.54 to 1.02 ), 0.07 \\
\hline Chorioamnionitis requiring antibiotics & $27(3)$ & $33(3)$ & 0.81 (0.49 to 1.34 ), 0.410 .78 (0.48 to 1.29 ), 0.34 \\
\hline Induction of labour & $390(36)$ & $378(35)$ & 1.02 (0.91 to 1.15$), 0.681 .03$ (0.92 to 1.15$), 0.63$ \\
\hline Antibiotics during labour & $439(41)$ & $454(43)$ & 0.96 (0.87 to 1.06 ), 0.430 .97 (0.88 to 1.07 ), 0.57 \\
\hline Caesarean section & $370(34)$ & $389(37)$ & 0.94 (0.84 to 1.06 ), 0.330 .95 (0.85 to 1.06 ), 0.34 \\
\hline Postpartum haemorrhage $>600 \mathrm{~mL}$ & $168(18)$ & $177(17)$ & 0.94 (0.77 to 1.14 ), 0.530 .94 (0.77 to 1.14 ), 0.50 \\
\hline 3rd/4th degree perineal trauma & $28(3)$ & $20(2)$ & 1.37 (0.78 to 2.43 ), 0.281 .36 (0.77 to 2.40 ), 0.29 \\
\hline Wound infection & $32(3)$ & $30(3)$ & 1.05 (0.65 to 1.72 ), 0.831 .04 (0.64 to 1.70$), 0.87$ \\
\hline Endometritis & $12(1)$ & $10(1)$ & 1.18 (0.51 to 2.72 ), 0.701 .18 (0.51 to 2.72 ), 0.69 \\
\hline Postpartum antibiotics & $99(9)$ & $98(9)$ & 1.00 (0.76 to 1.31 ), 1.000 .98 (0.75 to 1.28 ), 0.90 \\
\hline Mean (SD) postnatal length of stay (mother) (days) $\ddagger$ & $2.85(1.79)$ & $2.91(1.71)$ & 0.98 (0.93 to 1.03 ), 0.370 .97 (0.93 to 1.02 ), 0.31 \\
\hline Thromboembolic disease & $1(0.1)$ & $2(0.2)$ & $N A, 0.62 \S$ \\
\hline
\end{tabular}

$\mathrm{NA}=$ not applicable.

*Includes all liveborn infants.

†Adjusted analyses included stratification variables BMI category, parity, and centre.

$\ddagger$ Treatment effects are ratios of means based on imputed data.

$\S \mathrm{P}$ value derived Fisher's exact test. 
Table 5 | Post hoc analysis of maternal gestational weight gain in women with $\mathrm{BMI} \geq 25$ at trial entry by treatment group. Values are number/total available $(\%)$ and treatment effects are relative risks based on available data unless otherwise indicated

\begin{tabular}{|c|c|c|c|c|}
\hline \multirow[b]{2}{*}{ Gestational weight gain $(\mathbf{k g})$} & \multirow[b]{2}{*}{ Lifestyle advice } & \multirow[b]{2}{*}{ Standard care } & \multicolumn{2}{|c|}{ Treatment effect $(95 \% \mathrm{Cl}), \mathrm{P}$ value } \\
\hline & & & Unadjusted & Adjusted $^{*}$ \\
\hline Mean (SD) total† & $9.39(5.74)$ & $9.44(5.77)$ & $-0.05(-0.59$ to 0.48$), 0.85$ & $-0.04(-0.55$ to 0.48$), 0.89$ \\
\hline Mean (SD) average weekly $(\mathrm{kg}) \dagger$ & $0.45(0.28)$ & $0.45(0.28)$ & $0.00(-0.03$ to 0.03$), 0.94$ & 0.00 ( -0.03 to 0.03$), 0.99$ \\
\hline Below recommendations & $224 / 897(25)$ & $217 / 871(25)$ & 1.00 (0.85 to 1.18$), 0.98$ & 0.99 (0.84 to 1.15$), 0.86$ \\
\hline Within recommendations & $293 / 897(33)$ & $286 / 871(33)$ & 0.99 (0.87 to 1.14$), 0.94$ & $1.02(0.89$ to 1.17$), 0.75$ \\
\hline Above recommendations & $380 / 897(42)$ & $368 / 871(42)$ & 1.00 (0.90 to 1.12$), 0.96$ & 0.99 (0.89 to 1.10$), 0.85$ \\
\hline
\end{tabular}

*Adjusted analyses included stratification variables BMI category, parity, and centre. Outcomes derived from birth weight were additionally adjusted for maternal age, socioeconomic status and maternal smoking.

†Treatment effects are differences in means based on available data. 


\section{Figure}

\section{Eligible women approached to participate $(n=5474)$}

Women declined $(n=3262)$

Not interested ( $n=1304,40 \%)$

Too busy/other commitments ( $n=1011,31 \%$ )

Unable to contact $(n=652,20 \%)$

Other complications/belief in own diet/concern about diet focus/body image during pregnancy $(n=294,9 \%)$

\section{Women provided written consent and were randomised $(n=212)$}

Women randomised to lifestyle advice $(n=1018,50 \%)$ 1

Withdrew consent to use data $(n=3)$ Miscarriage before 20 weeks or termination of pregnancy $(n=25)$

Stillbirth after 20 weeks $(n=5)$

Liveborn infants $(n=1075)$

Neonatal deaths ( $n=4 ; 3$ lethal anomalies)

Maternal death $(n=1)$

\section{$\downarrow$}

Women (1080) and infants (1075) included in analysis
Women randomised to standard care $(n=1104,50 \%)$ $\downarrow$

Withdrew consent to use data $(n=7)$

Miscarriage before 20 weeks or termination of

pregnancy $(n=25)$

Stillbirth after 20 weeks $(n=5)$

Liveborn infants $(n=1067)$

Neonatal deaths $(n=1)$

Maternal death $(n=1)$

Women (1072) and infants (1067) included in analysis 